\title{
Perspectives on Knowledge Mobilization: An Introduction to the Special Issue
}

\section{Kimberly Matheson and Cathy Malcolm Edwards}

\author{
"A few years ago I shared an academic journal article I'd") \\ written with a colleague who worked for a provincial \\ government ministry and asked him, 'Do you think this \\ article will influence the policy cycle?' He laughed and said, \\ 'No - the decision makers above my level simply don't read \\ this kind of stuff.' That was a rude awakening! Since then \\ my goal has always been to try and influence policy and \\ practice more directly; that's not going to happen with \\ journal articles alone.
}

Rob de Loë

Water policy and governance researcher

\begin{abstract}
In this introduction to the Technology Innovation Management Review's special issue on Knowledge Mobilization, Guest Editors Kimberly Matheson and Cathy Malcolm Edwards share their different perspectives as an academic and a knowledge broker on the process of knowledge mobilization. Despite their distinctive points of entry into the knowledge mobilization field, they share a common perspective on the value of researchers and knowledge users learning from each other, working together to co-create solutions, and the importance of contributing back into the basic research and training of the next generation. They also provide the context of the authors' contributions to this special issue, noting that the articles are rooted in the authors' experiences in the health domain, but that they help to understand some of the challenges and rewards of integrating knowledge mobilization into research approaches more generally.
\end{abstract}

\section{Introduction}

What is knowledge mobilization? From our perspective, simply put, knowledge mobilization helps make research useful to society, and does so in a way that solution seeking can itself inform the research agenda. If you were to look for a common definition, however, you could easily become discouraged by the different terms reflecting slightly different variations on the theme: knowledge mobilization, knowledge translation, knowledge transfer. A new term, $\mathrm{K}^{*}$, has been created to help communities focus more on what the nature of the efforts are rather than getting lost in the terminology. What term is used often depends on the discipline, as well as the phase of the exchange between what constitutes knowledge and what constitutes action. The methodologies also differ substantially, depending on the context. Knowledge mobilization can be knowledgedriven, wherein researchers recognize that their empir- ical findings can have useful applications for developing useful technologies, approaches, or interventions to address problems. Conversely, it can be problem-driven, wherein there is a motivation to collect empirical knowledge in order to identify a solution. Often these motives come from different communities of practice, and too often, there are few bridges between them. One of the goals of this issue is to begin building such bridges, and to contribute to an approach that is more integrative - where researchers and knowledge users both contribute to the knowledge creation process, and both understand the context in which problems exist.

We have used this opportunity to share how we are approaching the promotion of knowledge mobilization as an integral part of research. As an academic (Kimberly Matheson) and a knowledge broker (Cathy Malcolm Edwards), we have different perspectives on the topic of knowledge mobilization. In what follows, we share our 


\section{Perspectives on Knowledge Mobilization: An Introduction to the Special Issue} Kimberly Matheson and Cathy Malcolm Edwards

different starting points, leading into how this special issue was shaped. The authors contributing to the issue have all framed their approach and what they have learned within the context of the various health case studies in which they played a role. This crossing of partnerships from different disciplines and sectors is never especially easy, and we anticipate that some of the experiences of the others contribute to a recognition that there are challenges, but that there also great benefits from working together to use research to address problems, and to learn for the development of solutions to shape our research directions.

In putting together this issue, we are hoping that the multiple knowledge mobilization efforts that have been implemented to address issues in the health domain raise as many questions for our readers as they provide answers. This approach is characteristic of the knowledge mobilization process - we are all learning. The process of going from knowledge to action is dynamic and is adapted to the social, cultural, political, and environmental contexts in which it is implemented. Sometimes it involves bringing together substantially different worldviews and taking the best from both (i.e., two-eyed seeing). Adapting solutions to a common problem in very different human contexts (e.g., the mental health of younger or older people) is a learning process that sheds light on our gaps of knowledge and unquestioned assumptions.

\section{An Academic's Perspective (by Kimberly Matheson)}

As a Canadian academic (although I am certain that this phenomenon is not limited to Canada), I have seen the concept of "knowledge mobilization" dominate the rhetoric around funded scientific research for at least the past 10 years. This approach emanates, in part, from demands for accountability from those who are paid by the public purse (either in the form of salaries or grant funding) to produce scholarship. The accountability pressures are coming from politicians, government ministries, and funding agencies, and presumably the general public. Superimposed on this background is an increasingly vocal student "clientele" who expect value for their dollar, and in particular that their education will provide them with access to top-paying jobs. Even without the cynicism regarding this sense of entitlement, there is the belief that academic jobs are scarce for those who exit their educational career with doctoral degrees and even postdoctoral experiences, and that these highly skilled graduates need to be pre- pared to work in the "real world" or be creative and entrepreneurial in their ability to adapt their skills to meet a financially-sustainable social or market demand. In short, whether we have appreciated or resented the expectation that our research have an impact, knowledge mobilization has become an important tool in the academic toolbox.

As researchers, however, it becomes apparent that, if we are to participate in knowledge mobilization, we must go beyond simply doing basic research and then disseminating it by posting a description on our website with a link to the too-often inaccessible jargonfilled journal article that may or may not be behind a paywall. The alternative does not mean "selling out" to commercialize one's intellectual property or becoming an expert consultant (although no doubt more than a few of us would not mind the potential financial benefits of such courses of action, if only we could figure out who would pay for it). Such approaches to end-state mobilization can (and do) work, but they are typically additional activities that are not integrated into the fundamental approaches we adopt as part of our research paradigms.

Just as many scholars have argued that working with students benefits their research, integrated knowledge mobilization can also be hugely rewarding and can have the capacity to transform our basic approaches. When we understand that there are significant health issues that cannot be solved by one person alone and therefore require teamwork, that even problems that seem to be singularly technical or biological are often determined and resolved as the result of an interplay of other forces (i.e., disciplines), the world becomes a fascinating, complex, and dynamically integrated organism that challenges us to go deeper or go broader, and fundamentally enriches our research and motivates us to keep digging. Integrated knowledge mobilization involves working with people who are not like "us" so that we can get a grasp on what the "big problem" is, and then much like putting together a puzzle without the picture on the box to guide us, we can work together to find a solution... only to discover that the puzzle we have been working on actually fits into another one that others have been working on. What could be more exciting to a scholar?

Sometimes we do not know where our research will bring us, but this is not inconsistent with integrated knowledge mobilization. To the contrary, in my own experience, the challenge of knowledge mobilization is 


\section{Perspectives on Knowledge Mobilization: An Introduction to the Special Issue} Kimberly Matheson and Cathy Malcolm Edwards

that I do not see from the outset which line of research will hold the key and where the research will land in terms of outcomes, and I have to be prepared for adapting directions if original expectations are either not working or the results are altered (moderated) by other unspecified factors in the situation. The parallels with basic research are clear. But there are differences. As a researcher committed to knowledge mobilization, I no longer "own" the problem or the solution. I bring my own tools to the table and look to see what is called for and what I can contribute. I work with others to determine what problems we will address next - I might be the lead, and I might not. In effect, knowledge mobilization is as much about learning and understanding where there is a pull for your expertise as it is about application and pushing out what you have produced. These are the synergies that make knowledge mobilization a worthwhile challenge for scholars and partners alike.

\section{A Knowledge Broker's Perspective (by Cathy Malcolm Edwards)}

After 10 years in the private sector, I decided to come work at a university because I wanted to be a part of something bigger - to make a difference in the world. I always believed that research had the power to transform society but I became frustrated through my experiences in the private sector, where research impact was measured in dollar signs or the almighty patent. I was attracted to the knowledge mobilization space because of connectedness: connectedness between research and impact and connectedness between people, values, and social good. For years, I was acting as a knowledge intermediary or broker between research and industry or not-for-profit organizations without knowing that there was an actual name for what I was doing. This role became key to crossing the divides between academia and the rest of the world. Researchers needed to find a strategy for getting uptake for the findings that excited them - the world outside of academia needed the expertise to help them have a positive impact.

Given the novelty of the role of knowledge broker, establishing strategies for sharing best practices (i.e., mobilizing knowledge mobilization itself) is why a special issue like this one is so important. It allows us to learn from one another's experiences so that we can all do a better job of moving knowledge into practice and products. Building information-sharing networks is also important in this regard, and there are numerous examples of such networks in Canada and internationally. For example, ResearchImpact (RIR; researchimpact.ca) is a pan-
Canadian knowledge mobilization network dedicated to maximizing the impact of academic research for public good in local and global communities (social, cultural, economic, environmental, and health). Development Research Uptake for Sub-Saharan Africa (DRUSSA) is a network of 22 African universities that are building capacity for universities to support knowledge mobilization (research uptake). Not only do networks connect knowledge brokers but they offer the supports for developing institutional capacities in knowledge mobilization by developing and sharing best practices, services, and tools.

As will be evident from some of the articles in this issue, it takes a willingness to let yourself be vulnerable to do meaningful knowledge mobilization. In order ensure that the relevant stakeholders get timely access to the information they need and for the "lived experience" of users/community to drive the project, you may need to put aside your personal agenda and to challenge your own disciplinary/sectoral approaches to become a part of something bigger. As noted earlier in this introduction, different sectors use different terms or may be focused on different elements of the $\mathrm{K}^{*}$ spectrum and somehow, for the benefit of the project, you will be required to navigate through the unknown. This is no easy task. A lot of the projects that I have worked on are dealing with complex social issues such as poverty, inequality, and climate change. Not only do they require cooperation across disciplines, they fundamentally affect our lives. As a member of a project team, you are called to remain objective, especially when there is passionate debate and discussion. It is important to allow all participants to see their voice represented in the outcomes, or the whole exercise can backfire. This process is facilitated through practices such as participatory action research and processes/tools such as design thinking.

The next generation of leaders is demanding support in acquiring the skills and necessary worldview to make a difference. Currently, I have the pleasure of working with students who are motivated and determined to be change makers. Each student had an idea of the social change that they wanted to create in the world - they had their "why" but were missing the "how". With other non-academic partners, the students are learning entrepreneurial and critical thinking skills that will translate to starting up their own social enterprises, affecting policy change, or acting as intrapreneurs in organizations needing a culture shift. Each one of the students is ready to make change - they will become 21st century 


\section{Perspectives on Knowledge Mobilization: An Introduction to the Special Issue} Kimberly Matheson and Cathy Malcolm Edwards

knowledge brokers, connecting ideas to practice and practice to impact. If we do this right, soon we will have as much to learn from this new generation as they have to learn from us today.

\section{About This Special Issue}

There already exist numerous broad-based publications regarding the process of knowledge mobilization, various templates and tools that can be used to set about incorporating knowledge mobilization into a research design, and case studies that describe the impact of research through the process of participatory research designs. This special issue is intended to complement existing research by pointing to some key elements that are sometimes overlooked in terms of their importance, or sometimes not talked about at all, resulting in a sense of disillusion among researchers and stakeholders alike. In this issue, we examine to the importance of systems-level thinking from different viewpoints.

In the first article, Melanie Barwick, Head of the Child and Youth Mental Health Research Unit at The Hospital for Sick Children in Toronto, Canada, describes the development and application of the Knowledge Transition Planning Template, which supports knowledge transition planning for scientists in health and other sectors. She discusses how the user-driven field of healthcare led to a change in frameworks for funding health research, which in turn, led to the change across government funding agencies wanting to see the direct benefit to everyday Canadians. She also highlights that, in order for this framework to be successful, capacity building is a must.

In the second article, Gabriel Moore and colleagues from the Sax Institute and Movember Foundation also represent the perspective of systems change within an organization. The Movember Foundation set out to facilitate knowledge translation/mobilization through their grants process in order to ensure that the knowledge generated through their funding reaches the appropriate knowledge users. These authors provide insights and resources for those who are trying to develop a strong knowledge mobilization strategy.

It is hard to find a field where the importance of the end user is more prevalent than in health. Even when we think we have got it right, we sometimes encounter challenges that are not addressed in knowledge mobil- ization templates or frameworks. As a strategy for anticipating the unanticipated, Chantal Trudel at Carleton University in Ottawa, Canada and her colleagues at the University of Nottingham, England, and the Ottawa Hospital in Ottawa, Canada, demonstrate the value of a human-centric approach throughout the research including in the pre-design phase. This approach enables better identification of what users actually need, in this case, to meet the requirements with respect to hand washing and attenuating spread of infectious disease in neonatal units. Trudel and colleagues note that solutions that were "obvious" to designers were not perceived as viable, and that pre-design research helps anticipate when ready-made solutions are not going to work. They argue for a multi-method approach that provides rich data.

Another critical issue in the knowledge mobilization process is to provide timely information to end users. Edward Lemaire at The Ottawa Hospital Research Institute's Centre for Rehabilitation Research and Development reflects on the pace of change for assistive devices and how current research methods cannot keep up. Using carbon-fibre ankle-foot orthoses as a case study, Lemaire introduces the challenges rehabilitation specialists face when confronted with trying to select from the almost 70 different devices on the market and to anticipate the expected clinical outcomes for a target population. New methodologies are needed to support evidence-based decision making that balances both the need for controlled research with the need for timely decision making.

Indeed, timing can be everything to researchers and developers too. Renate Ysseldyk and Angela Paric from Carleton University, together with Tracy Luciani from Artswell in Ottawa, Canada, share their insights regarding the process of applying evidence-based theory to develop interventions to improve the well-being of hospitalized older adults (some with dementia). Ysseldyk and her colleagues highlight how community-based research can benefit the participants, but benefits to the objectives of researchers and developers are sometimes slow in coming. In particular, the authors share their experience of trying to implement and assess an intervention within a complex care context, and the many challenges encountered, ranging from shifting institutional priorities to ethical considerations. These factors can require a considerable time investment at the front end of the process, and can even result in a shift in the objectives or scope of the research itself. 


\section{Perspectives on Knowledge Mobilization: An Introduction to the Special Issue}

\section{Kimberly Matheson and Cathy Malcolm Edwards}

A readiness to reconsider one's research objectives might also be an inherent aspect of knowledge mobilization that attempts to address "hot" or contentious issues. Susan Braedley, at Carleton University shares her work in the highly politicized world of unionized and sectored emergency services and highlights the need for stakeholders to share common values that can guide decision making throughout the knowledge mobilization process. Braedley notes the need to talk about the potential flashpoints when providing training or encouragement in knowledge mobilization. Politics can result in partners having to compromise values or walk away, and diminishing the likelihood of such a choice being made points to the need to have a clear articulation of goals, engaging different perspectives, and sharing information throughout the process. No doubt Braedley's experiences will resonate with academic and stakeholder partners alike.

\section{Conclusion}

This issue is not intended to be a comprehensive template or guidebook to knowledge mobilization. Many of these already exist and are easily accessible online. Instead, we want to provide readers with a sense of optimism regarding some of the challenges others are encountering as they embark on the difficult task of transcending perspectives, paradigms, and sector-specific priorities to be able to come to a common understanding of what is needed to create solutions. How can optimism come from sharing challenges? Because it creates an opportunity to learn from each other, a recognition that these challenges are par for the course and not a function of our own abilities, and that when you come out the other end, the value of the effort was worth it.

\begin{abstract}
About the Authors
Kimberly Matheson is the Joint Research Chair in Culture and Gender Mental Health at the Royal Ottawa's Institute of Mental Health Research and Carleton University. She is also a Professor in the Department of Neuroscience, and the founding Director of the Canadian Health Adaptations, Innovations, \& Mobilization (CHAIM) Centre at Carleton University in Ottawa, Canada. She is a health psychologist that brings a recognition of the critical role that social determinants play in the health and well-being of disadvantaged or marginalized populations. Her recent work is in partnership with communities and organizations in Northwestern Ontario to promote resilience and well-being among First Nations youth.
\end{abstract}

Cathy Malcolm Edwards is Managing Director of 1125@Carleton and has an enthusiastic appreciation for the power that research has to improve lives and the world we live in. Her client-centric approach fosters open dialogue, promotes collaborative engagements and encourages successful relationship management practices. As Managing Director of 1125@Carleton, Cathy provides strategic direction as well as guidance to and opportunities for collaborative research and engagement. She is also cofounder of the Born Social Fellowship, a leadership program that inspires youth to create a more just and sustainable world through action and impact.

Citation: Matheson, K., \& Edwards, C. M. 2016.

Perspectives on Knowledge Mobilization: An

Introduction to the Special Issue. Technology Innovation

Management Review, 6(9): 4-8.

http://timreview.ca/article/1014

Keywords: knowledge mobilization, health, partnerships, interdisciplinary 